\title{
The experimental testing of semi-authomated process of degraded DNA extraction and reading on ancient samples from Baltic area
}

\author{
Vsevolod Merkulov ${ }^{1}$, Vladimir Kulakov ${ }^{2}$ and Alexander Semenov ${ }^{3,4, *}$ \\ ${ }^{1}$ International scientific journal Historical format, Moscow, Russia \\ 2 Institute of Archeology of the Russian Academy of Sciences, Moscow, Russia \\ ${ }^{3}$ Moscow Technological Institute, 38a Leninsky prospect, Moscow, Russia \\ ${ }^{4}$ Deep Dive Group, Moscow, Russia
}

\begin{abstract}
The extracting the genetic information from old and degraded DNA now become a serious and promising direction of biotechnology. In Russia, this kind of technological systems is fully developing only recent years, so building and testing the processes for degraded DNA extraction and reading is still important, as it makes Russia independent from foreign laboratories. Below we outline the authomated process designed and performed in Russia, and mainly the result of the experiment on Y-DNA haplogroup defining of two ancient burials from Kaliningrad Area. The obtained data allows defining the Y-haplogroup R1a with a certain probability. The paper outlines the experiment, testing process, and the obtained results for both samples in form of precise but scarce data. The experiment showed that the developed system manages with 1000-1500 year old samples preserved in acid soils prevailing in Russia. The technology mentioned and used in the test was developed in Moscow Institute of Physics and Technology by the Laboratory of Historical Genetics, Radiocarbon Analysis, and Applied Physics and was used in the project according to the agreement.
\end{abstract}

\section{Introduction}

The paleoDNA testing becomes one of the challenging branches of modern biotechnology. Modern technology processes allow high-quality DNA extracting and testing by various number of methods including Y-chromosome and mitochondrial DNA haplogroup defining. The results are used in forensic, archaeological, and criminalistics needs. In archaeology they can give a valuable insight for defining the affinity of an ancient population to other ancient and modern population groups. In criminalistic and forensic works it can be a good tool for kinship and in some cases person's origin estimation.

The field of study of ancient DNA (aDNA) extracted from museum specimens and archaeological and paleontological samples began about 30 years ago [1]. The main aim was to determine the nucleotide sequence of short mitochondrial DNA (mtDNA) fragments. The development of new DNA extraction techniques and subsequent bioinformatics analysis has made it possible to reconstruct the complete full-scale genomes of ancient organisms [2]. These techniques have helped researchers to draw conclusions about the organisms that became extinct tens to hundreds of thousands years ago as well as also about the population structure of those species. Nowadays, studies of aDNA have become an important tool for testing evolutionary hypotheses and allowing the complex reconstruction of the history of biota changes. Special attention has been paid to the study of nucleic acids extracted from human remains, as this helps researchers to answer many important questions.

Despite these technological advances, certain technical and methodological problems exist that are specific to aDNA, arising primarily from its high degree of degradation and the presence of the so-called postmortem modifications of nucleotide bases, as well as the small quantities of authentic DNA normally available to be studied. One of the most noticeable changes in the aDNA structure is the deamination of nucleotides, which leads to substitutions of bases in the polymerase chain reaction (PCR) process: cytosine to uracil, 5methylcytosine to thymine (both variants lead to incorporation into the growing chain of thymine instead of cytosine), and, more rarely, adenine to hypoxanthine (causing inclusion of guanine instead of adenine) [3-5]. Another very serious obstacle to studying aDNA is the contamination of ancient samples by the DNA of other organisms [6-9]. To manage these issues, researchers over the years have developed several guidelines to ensure the quality of aDNA data and the reliability of conclusions drawn, which resulted in the nine "gold criteria" outlined by Cooper and Poinar in "Ancient DNA: do it right or not at all" [10]. These criteria include points such as a physically isolated work area to prevent intra-laboratory contamination, multiple negative controls to reveal contamination, if it occurs, and a molecular behavior test to detect whether characteristics of the sample DNA match the degradation pattern or not. 
In Russia a successful work of building an authomated genetic testing system and process of old degraded DNA was done in Moscow Institute of Physics and Technology by the Laboratory of Historical Genetics, Radiocarbon Analysis, and Applied Physics (headed by Dr. Kh.Kh. Mustafin).

In the Laboratory it was introduced an approach for aDNA extraction and sample preparation that helps minimize intra-laboratory contamination. The only way to avoid intra-laboratory contamination of aDNA samples is to physically isolate them from other samples that are prepared in a laboratory and from each other during the sample preparation procedure [11]. To manage this issue, in the ideal case, the laboratory should have several extremely clean rooms connected by transmission locks and to be used only for works with ancient samples, which is difficult to afford in general. The sterile box system is located in a single room but offers four independent sterile areas isolated from the environment, which can be completely cleaned after processing of each sample. Thus, it is much easier to maintain such small "laboratories" under sterile conditions. Using the glovebox, it is possible to conduct all stages of sample preparation, including modern human DNA samples.

To test its possibilities a series of experiments of testing ancient degraded samples was undertaken.

The method was also used earlier and results were described in work [12] (test was done in 2016), but the previous sample was not as old as current (300-400 years old), and the process was then still in design. The aim of the current experiment was to test whether the existing process manages with much older samples, to test the current technical kit, and to design more precise process in the near future taking into account the results obtained.

The two ancient samples for this experiment were excavated in Kaliningrad Area of Russia by the Baltic archaeological expedition lead by V.I. Kulakov [13]. The sample Do-367 (Dollkeim-Kovrovo) was extracted from the oval urn pit. The urn contained small fragments of calcined bones of Do-367 male burial (described in [15]). The preliminary date is late Roman time (IV-VI century) (fig. 1).

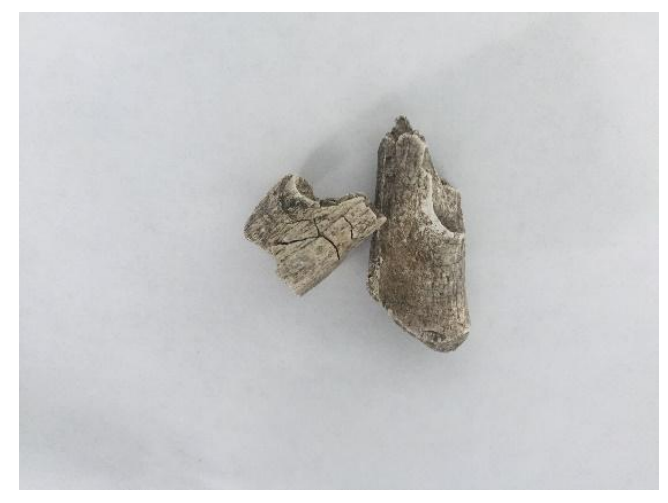

Fig. 1. The photo of the sample 1 (Do-367).
The sample 2 Y-68 from Yrzekapinis/Klinstovka-1 is a two-level burial in oval tomb, oriented from northeast to south-west [14]. The preliminary date is Early Middle Ages (XI century) (fig 2). It is younger than the sample 1 but it was less preserved (in absence of better samples in the available collection).

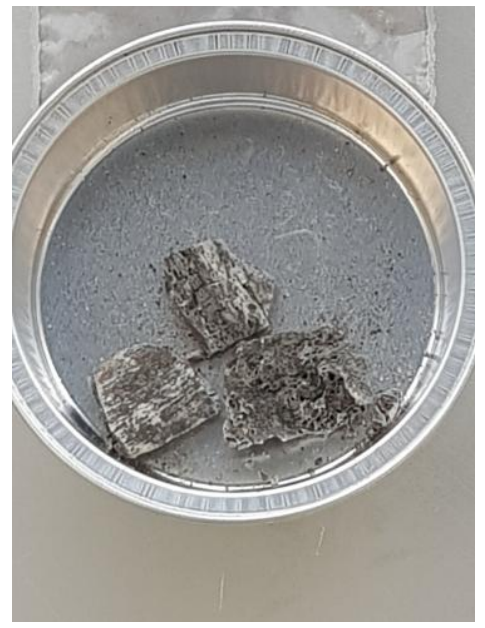

Fig. 2. The photo of the sample 2 (Y-68).

It was decided to use these calcined samples to test the technology in complicated environment, where DNA would certainly be degraded. Nevertheless, to mitigate risk, a sample rather large by size were taken.

\section{Experimental Design, Materials, and Methods}

The DNA was extracted by means of the commercial kit PrepFiler BTA Forensic DNA, what is used in criminalistics and forensic medicine for the extraction of degraded DNA from complicated objects. So, a partially authomated process was developed and the system was assembled by the Laboratory of Historical Genetics, Radiocarbon Analysis, and Applied Physics headed by Dr. Kh.Kh. Mustafin as the unique complex containing the glove boxes (fig. 3). The main part is a specially designed glovebox module that maintains a high purity nitrogen atmosphere, allowing DNA extraction in ultraclean conditions.

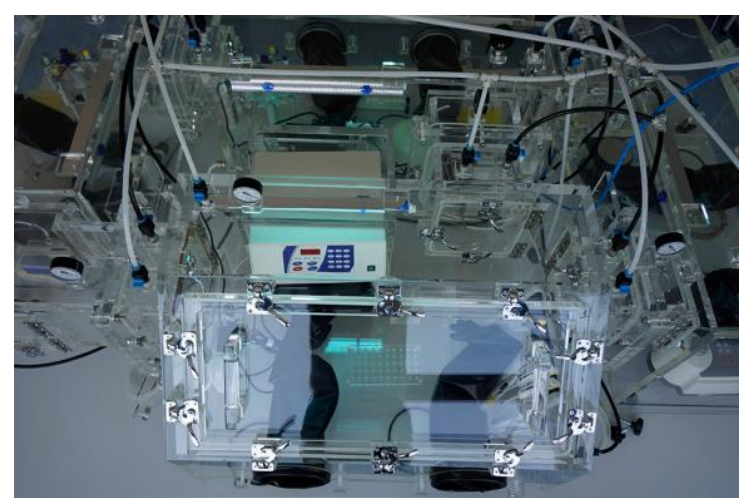

Fig. 3. The system (glovebox_used in the experiment) [15]. 
Below we outline the resulting process.

The work contained the following stages:

- preparing of equipment and tools;

- the cleaning of the sample from contamination;

- grinding the sample to a powdery state;

- extraction of DNA from a ground sample;

- measuring the concentration of DNA;

- carrying out PCR and capillary electrophoresis of PCR products to determine the STR loci of the Y chromosome (27 STR loci).

All stages of work with the archaeological sample were carried out in glove boxes, in which the atmospheric air was replaced by an inert gas of high purity. That included the following stages (for the sample 1):

1. Sterilization of all instruments and working space in the boxes with the help of chemicals and hard UVirradiation within 24 hours.

2. The primary mechanical cleaning of the ancient bone from the surface layer of impurities on specialized equipment with milling cutters and secondary cavitation cleaning with ultrasound.

3. Grinding of the purified bones in a ball mill. As a result, a bone powder weighing $3.40 \mathrm{~g}$. was obtained.

4. DNA extraction from the bone material was carried out 2 times by 2 different methods - the phenol extraction method and the method based on silicone.

5. The resulting DNA concentration was $0.9 \mathrm{ng} / \mu \mathrm{l}$. This concentration contained DNA fragments from 20 to $180 \mathrm{bp}$ in length. During the PCR reaction, STR fragments of the Y chromosome from 90 to $180 \mathrm{bp}$ in length were successfully amplified. Fragments of greater length did not survive due to DNA degradation in the sample Do-367.

6. As a result of electrophoresis of PCR products on the capillary sequencer AB3500xl and analysis of phoreogram (Fig 4), 7 STR loci of the Y chromosome with the values of the alleles indicated in Table 1 were reliably detected.

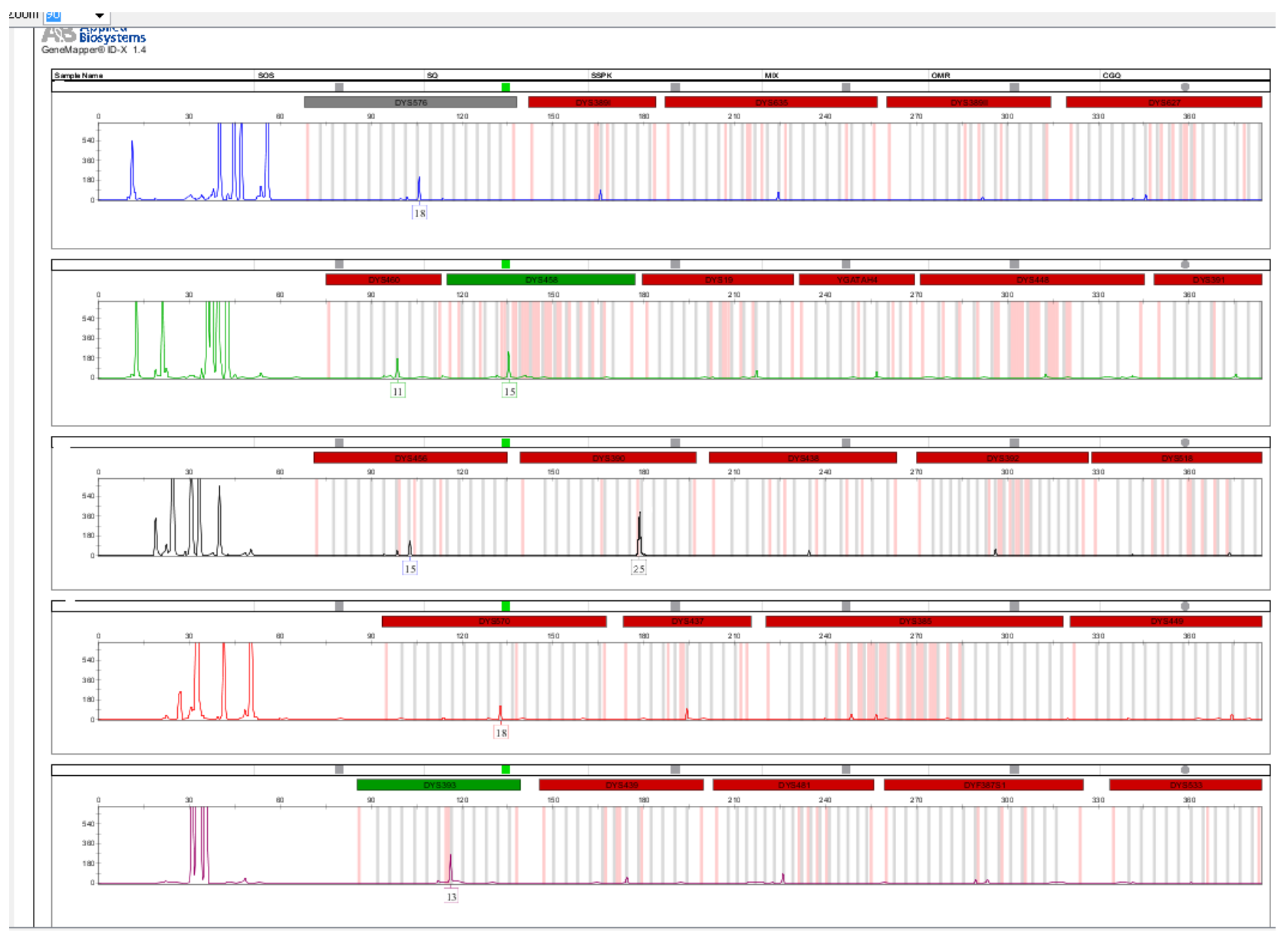

Fig. 4. The phoreogramm of the experiment for the sample 1

Analogically, the same procedure for the sample 2 yielded the following results, less impressive than for the sample 1 due to the worse preservation. Mass of obtained bone powder was $0,7 \mathrm{~g}(>1,0 \mathrm{~g}$ required to assure the robustness). The resulting DNA concentration was $0.3 \mathrm{ng} / \mu \mathrm{l}$. ( $>0,5 \mathrm{~g}$ required) The small concentration makes the result to be only of preliminary character, but 2 loci were firmly estimated. The result on sample 1 can be considered as robustly estimated.

\section{Data and interpretations}

The experiment resulted in following data (table 1). 
Table 1. STR loci of the Do-367 sample

\begin{tabular}{|c|c|c|c|c|c|c|c|}
\hline \multicolumn{7}{|c|}{ STR loci obtained } \\
\hline & 393 & 390 & 458 & 460 & 456 & 576 & 570 \\
\hline Do-367 & $\mathbf{1 3}$ & $\mathbf{2 5}$ & $\mathbf{1 5}$ & $\mathbf{1 1}$ & $\mathbf{1 5}$ & $\mathbf{1 8}$ & $\mathbf{1 8}$ \\
\hline
\end{tabular}

The definition of Y-haplogroup with 7 loci according to the predictor HPRG.com http://www.hprg.com/hapest6/files/hapest6.htm?order $=$ o rig ) gives a very high probability $(83 \%)$ of R1a haplogroup. The full list of haplogroups and probabilities is given below in the table 2 .

Table 2. The prediction of Y-haplogroup according to the experimental data for the Do-367 sample.

\begin{tabular}{|c|c|}
\hline Haplogroup & Probability (\%) \\
\hline E1a & 0.0 \\
\hline E1bla & 0.0 \\
\hline E1blb & 1.2 \\
\hline G1 & 0.0 \\
\hline G2a & 0.0 \\
\hline $\mathrm{G} 2 \mathrm{~b}$ & 0.0 \\
\hline I1 & 0.0 \\
\hline $\mathrm{I} 2 \mathrm{a}$ & 0.2 \\
\hline $\mathrm{I} 2 \mathrm{~b}$ & 0.1 \\
\hline $\mathrm{J} 1$ & 0.0 \\
\hline $\mathrm{J} 2 \mathrm{a}$ & 0.0 \\
\hline $\mathrm{J} 2 \mathrm{~b}$ & 0.0 \\
\hline $\mathrm{L}$ & 0.0 \\
\hline $\mathrm{N}$ & 0.0 \\
\hline $\mathrm{O}$ & 0.0 \\
\hline Q & 0.1 \\
\hline R1a & 83.0 \\
\hline $\mathrm{R} 1 \mathrm{~b}$ & 15.5 \\
\hline $\mathrm{R} 2$ & 0.0 \\
\hline $\mathrm{T}$ & 0.0 \\
\hline
\end{tabular}

For the sample 2 the definition of Y-haplogroup with 2 loci (DYS392=11, DYS438 =11) according to the predictor HPRG.com http://www.hprg.com/hapest6/files/hapest6.htm?order $=$ o rig ) gives a high probability $(66 \%)$ of R1a. The full list of haplogroups and probabilities is given below in the table 3.

This correspond to the proposed affinity of ancient population of Kaliningrad district to other Eastern European populations.
Table 3. The prediction of Y-haplogroup according to the experimental data for the Y-68 sample.

\begin{tabular}{|c|c|}
\hline Haplogroup & Probability (\%) \\
\hline E1a & 0.0 \\
\hline E1b1a & 11.6 \\
\hline E1b1b & 16.3 \\
\hline G1 & 0.0 \\
\hline $\mathrm{G} 2 \mathrm{a}$ & 1.5 \\
\hline $\mathrm{G} 2 \mathrm{~b}$ & 0.1 \\
\hline I1 & 2.3 \\
\hline $\mathrm{I} 2 \mathrm{a}$ & 0.9 \\
\hline $\mathrm{I} 2 \mathrm{~b}$ & 0.0 \\
\hline $\mathrm{J} 1$ & 0.5 \\
\hline $\mathrm{J} 2 \mathrm{a}$ & 0.2 \\
\hline $\mathrm{J} 2 \mathrm{~b}$ & 0.0 \\
\hline $\mathrm{L}$ & 0.0 \\
\hline $\mathrm{N}$ & 0.0 \\
\hline $\mathrm{O}$ & 0.1 \\
\hline Q & 0.1 \\
\hline R1a & 66.2 \\
\hline R1b & 0.1 \\
\hline $\mathrm{R} 2$ & 0.2 \\
\hline $\mathrm{T}$ & 0. \\
\hline
\end{tabular}

\section{Discussion}

In this study, we outline the result of the experiment for a novel approach to work with aDNA, which consisted of isolating the sample in a specially designed module system that maintains a high purity nitrogen atmosphere, allowing DNA extraction in ultra-clean conditions. Furthermore, the collective of the Laboratory designed a sample preparation protocol for massive parallel sequencing using non-standard modified sequencing adaptors, enabling us to obtain a library of fragments from extremely low amounts of starting degraded material.

The DNA was isolated from the remains that were found in the Baltic Region; soils in this region are highly acidic. The bones were calcined and seriously older than in previous experiment (300-400 years ago, Central Russia).In addition, severe weather conditions in this region do not contribute to the preservation of genetic material in the remains. Seasonal fluctuations causing high/low temperatures and increased humidity destroy bone tissue enabling chemicals and microorganisms to damage DNA. It was compared the level of DNA damage in the two samples with that mentioned in published data and it was found that the level corresponds to that in much older remains, which were stored in more favorable conditions.

The experiment showed that the technical process and semi-authomated system for genetic testing is working for much older samples that were tested before (more than 1200 years in difference).

For the previous sample [12], 23 markers were obtained. The current result is less informative due to higher degree of degradation which is stronger with 
respect to the age and conditions of preserving. Of course, 7 of 27 tested loci seems far from compete test, so the direction of the future work of the Laboratory will be the further improvement of the accuracy what may result in newer architectures, reactive kits, and processes. The sample 2 was more seriously degraded and the 2 loci obtained are considered to be rigid but incomplete result. So, of course we see that highlydegraded samples yield serious loss in quality what signals for a need to improve the technology.

The problem is really important for Russia as much of the both old and recent burials quickly degrade due to high acid soils, and it is often hard to obtain accurate result either for archaeological or forensic and criminalistics needs. That problem is existent even for «new» 100-200 years old samples.

Another challenge is to learn to extract more information from the lesser amount of DNA as in practice often only lesser parts of bones are available for research and DNA analysis.

\section{Conclusions}

We can conclude that the experiment was proper and the positive result was obtained. Nevertheless we see that even in the improved conditions the capacity of the system falls drastically so for the needs of solving tasks for Russian acid soil the system and process should be still improved. As a conclusion, the experiment showed that the method developed in Moscow Institute of Physics and Technology is working in degraded samples and can be a good base for future development. The technology of a glovebox and new technological processes proved to be a good solution for an old and destructed DNA research.

All the technical information about the system and technology itself are described by its authors Dr. Kh.Kh. Mustafin and his team in the paper [15].

The authors appreciate E. Loytsker, S.Senicheva, E. Shcherbinina, I. Rylshikov, E.Payor, D.Votrin, A.Zubko, Andr. Semenov for financial contribution for the research.

The reseach was done by the Laboratory of Historical Genetics, Radiocarbon Analysis, and Applied Physics according to the agreement №DNA-CA/12-17 dated 26.12.2017.

\section{References}

1. S. Paabo, Proc Natl Acad Sci USA, 86, 1939 (1989)

2. J. Krause, L. Orlando, D. Serre, B. Viola, K. Prufer, M.P. Richards, J.J. Hublin, C. Hanni, AP. Derevianko, S. Paabo, Nature, 449, 902 (2007)

3. M.T. Gilbert, A.J. Hansen, E. Willerslev, L. Rudbeck, I. Barnes, N. Lynnerup, A. Cooper, Am J Hum Genet, 72, 48 (2003)

4. M.T. Gilbert, A.J. Hansen, E. Willerslev, L. Rudbeck, I. Barnes, N. Lynnerup, A. Cooper Am J Hum Genet, 72, 32 (2003)

5. M. Hofreiter, V. Jaenicke, D. Serre, A. von Haeseler, S. Paabo, Nucleic Acids Res, 29, 4793 (2001)

6. J.J. Austin, A.B. Smith, R.H. Thomas, Trends Ecol Evol, 12, 303 (1997)

7. G. Gutierrez, A. Marin, Mol Biol Evol, 15, 926 (1998)

8. H Nicholls, PLoS Biol, 3, e56. (2005)

9. H. Zischler, M. Hoss, O. Handt, A. von Haeseler, A.C. van der Kuyl, J. Goudsmit, Science, 268, 1192 (1995)

10. A. Cooper, H.N. Poinar, Science, 289, 1139 (2000)

11. T.L. Fulton, Methods Mol Biol, 840, 1 (2012)

12. Kh.Kh. Mustafin, I.E. Alborova, A.S. Semenov, V.I. Vishnevsky, RUSIN, 1(47) (2017)

13. V.I. Kulakov, Dollkeim-Kovrovo. Research of $1992-$ 2002 (Minsk, Historical Institute of Belarusian National Academy of Sciences, 2007).

14. V.I. Kulakov, Stratum plus: Archeology and cultural anthropology, 5, 211 (1999)

15. A.D. Matsvay, I.E. Alborova, E.V. Pimkina, M.L. Markelov, K. Khafizov, K.K. Mustafin, Experimental approaches for ancient DNA extraction and sample preparation for next generation sequencing in ultra-clean conditions (Conservation Genetics Resources, 2018) 